\title{
A Premiere example of the illusion of harm reduction cigarettes in the 1990s
}

\section{R W Pollay, T Dewhirst}

See end of article for authors' affiliations

Correspondence to Richard W Pollay, Faculty of Commerce and Business Administration, 2053 Main Mall, University of British Columbia, Vancouver, BC V6T 1Z2, Canada; pollay@commerce.ubc.ca

Received

25 November 2002

Accepted 16 June 2003
Objective: To use the product launch of Player's Premiere as a case study for understanding the new cigarette product development process during the 1990s. We determine the (in)validity of industry claims that: (1) development of the physical product preceded the promotional promise of "less irritation"; (2) "less irritation" was actually realised; (3) advertising informed consumers; and (4) advertising regulations caused the product's failure in the marketplace.

Setting: Court proceedings assessing the constitutionality of Canada's Tobacco Act, which substantially restricts cigarette advertising. The 2002 Quebec Superior Court trial yielded a new collection of internal documents from Imperial Tobacco Ltd (ITL), including several about the development and marketing of Player's Premiere.

Method: Trial testimony and corporate documents were reviewed to determine the validity of the industry representations about the new cigarette product development process, focusing on the case history of Player's Premiere.

Results: In direct contradiction to industry testimony, the documentary evidence demonstrates that (1) communications for Player's Premiere, which claimed less irritation, were developed long before finding a product that could deliver on the promise; (2) ITL did not sell a "less irritating" product that matched its promotional promise; (3) the advertising and other communications for Player's Premiere were extensive, relying on the hi-tech appearances ("tangible credibility") of a "unique" filter, yet were uninformative and vague; and (4) Player's Premiere failed in the marketplace, despite extensive advertising and retail support, because it was an inferior product that did not live up to its promotional promise, not because of regulation of commercial speech.

Conclusions: New product development entails extensive consumer research to craft all communications tools in fine detail. In the case of Player's Premiere, this crafting created a false and misleading impression of technological advances producing a "less irritating" cigarette. This product was solely a massive marketing ploy with neither consumer benefits, nor public health benefits. The industry attempted to deceive both consumers and the court.
$\mathrm{N}$ ew product development in the tobacco industry has a long history of products employing new technologies (for example, filters), additives (for example, ammonia, menthol), forms (for example, $100 \mathrm{~mm}$, slims), and apparent tar yields (for example, lights). Many of these new product varieties seem to have been offered in response to health concerns of smokers, offering them a presumption of reduced risk. When filtered cigarettes were first sold aggressively in the 1950s, numerous ads explicitly promised "health protection". Subsequent advertising became more indirect and implied healthfulness or communicated it symbolically. Despite the claims made in many ads, several filtered products delivered as much tar and nicotine as the unfiltered ones they were meant to improve upon. ${ }^{1}$ In the 1970s, so-called "light" cigarettes delivered lower machine measured yields, and were consumed with misguided faith that this implied reduced risk..$^{2-4}$ Then and now, and in many jurisdictions, products are described with health oriented descriptors like bio-filters (fig 1), in ads calling attention to hi-tech filters (fig 2), or those that are supposedly "unique". ${ }^{5}$ New technologies create cigarette-like products, such as Eclipse. ${ }^{6}$ Throughout this product evolution there has been the persistent question of just how real is the apparent harm reduction. ${ }^{7}$

Insight into the more contemporary cigarette product development process can be obtained from a case study of the development of Player's Premiere, which was promoted as a product with "less irritation". ${ }^{8}$ Canada's Tobacco Act was enacted on 25 April 1997 and restricts Canadian cigarette promotion. ${ }^{9}$ While sponsorship forms of advertising may continue until October 2003, the Tobacco Act otherwise prohibits advertising of a lifestyle nature or likely to be of special interest to minors. The communication of product relevant information in text based formats remains permissible. The trial to assess the industry's constitutionality challenge occurred in the Quebec Superior Court (Montreal) during 2002 and is the source of the evidence below, with references to the trial's testimony pages and document Bates numbers shown parenthetically. The documents produced during this litigation allow for the (in)validation of the industry's representations about new products and their development process.

\section{Imperial Tobacco Ltd and the Player's brand family} Canada's cigarette industry is a small oligopoly of just three firms, and Imperial Tobacco Ltd (ITL) —owned by British American Tobacco (BAT) and therefore a Brown \& Williamson $(B \& W)$ affiliate-now dominates with a $70 \%$ market share. Despite this success, ITL continues to strain for ever more, hoping to maintain the $1 \%$ per year average share growth they have enjoyed since the mid 1970s (1340), since "one incremental share point will give us [ITL] twenty million dollars [C $\$ 20,000,000]$ in profit" (1632). "Generally speaking, we know that the vast majority of our share growth is going to come from new brands" (1452).

Player's and du Maurier are the flagship trademarks for ITL, evident by the fact that they are the two best selling cigarette brands in Canada. Collectively, Player's and du Maurier hold 


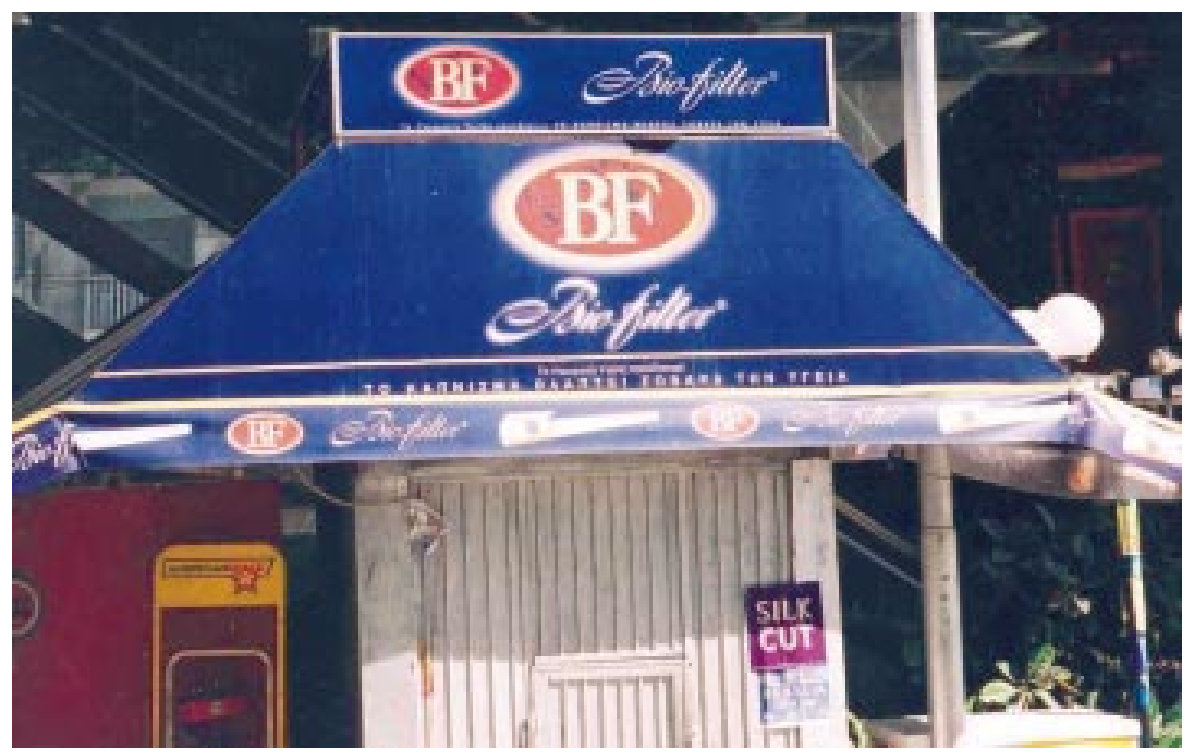

Figure 1 BF Bio-filter retail awning (Greece 2001).

an impressive $60 \%$ share of the Canadian cigarette market. The Player's brand family currently consists of Plain, Filter, Medium, Light, Light Smooth, Extra Light, Special Blend, John Player Special, and Silver. Player's Premiere was a line extension whose development began in 1993, with test markets in 1996, and full national launch early in 1997. It was presented as an innovative product yielding less irritation because of its unique filter.

\section{TESTIMONY BY THE ITL EXECUTIVE}

Ed Ricard of ITL was the only tobacco industry executive to testify at the 2002 Quebec Superior Court trial. Ricard has worked his entire professional life in various marketing roles for ITL, a firm his father once led as CEO. With two decades of experience, he testified that there was no area of marketing and communications effort by ITL that he had not experienced (1295). At the time of trial, Ricard was in charge of strategy and product development..$^{10}$

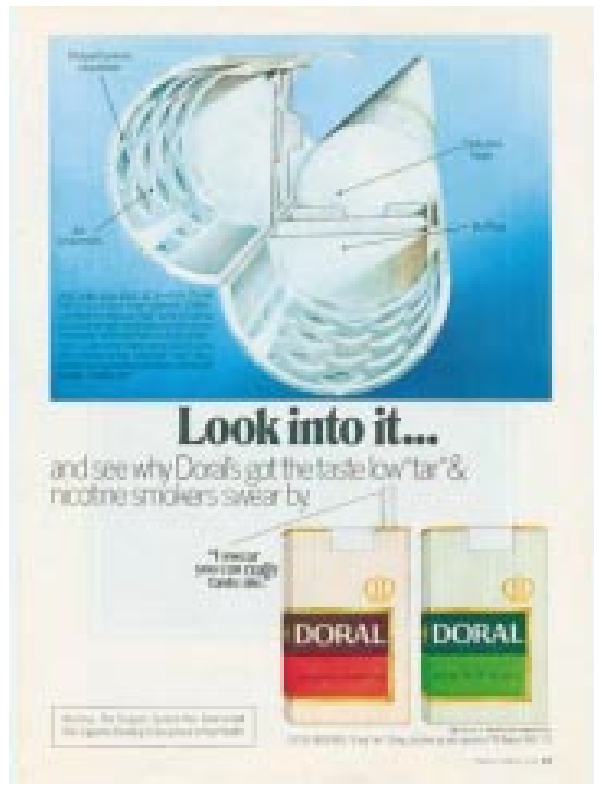

Figure 2 Doral ad. "Look into it" (unique chambered filter) (USA 1973).
The importance of image management

ITL's resurgence since the mid 1970s was attributed to an adoption of a brand planning process and understanding "a lot more about product positioning and image positioning" (1338). Product and image positioning refers to the place a product, brand, or group of products occupies in consumers' minds relative to competing offerings. Products are often associated with abstract qualities, such that brands are considered to have personalities. ${ }^{12}{ }^{13}$ Player's, for example, has been very successfully promoted to young males as an expression of independence, freedom, self expression, and masculinity. ${ }^{14} 15$

Brand images have been extensively studied by ITL since the mid-1970s. "Project Image" is an annual research effort, with a methodology standardised since 1982. Consumer perceptions are measured using lengthy face-to-face interviews with 2000 smokers who rate all of the market's trademarks and brands on many diverse attributes. "And as far as I'm concerned, in the job that I do at Imperial Tobacco, it's the most critical information that I have, it's this trademark and brand image information" (1347).

This research-its instruments, procedures, and analysiswere explained to the court in considerable detail, albeit with exhibits censored (redacted) ostensibly for competitive reasons (1348-81). Trademark and brand attributes are measured using a Likert nine point scale. When analysed, these are sorted into physical attributes (that is, product dimensions such as strength, irritation, and taste) and non-physical attributes (that is, user and image/identity dimensions such as youthfulness, masculinity, and popularity). This information is used both (1) to identify clusters of closely competing brands, and (2) to segment the market by analytically aggregating consumers with similar perceptions, desires, and concerns. ${ }^{16}$

Project Image also includes data about respondents' "ideal brands". These data are utilised to identify new product development opportunities with respect to either product performance and/or brand personalities. The benefit segmentation "uncovers opportunities for us to position a new entry into the market" (1380). The tools available for realising the positioning objective are packaging, sponsorship communications, in-store displays and, as allowable, conventional advertising (1568-9). The claim that "the advertising gives them [consumers] information on the image of the product" (1345), we note, employs an extremely loose definition of what constitutes product information. 


\section{Ad scrutiny and approvals}

The research development process uses multiple waves of focus groups to assess even the finest of advertising details. For new products, this effort is directed toward "all of the aspects of that new brand, including the advertising" (1575). Ricard estimated that in deciding upon a final ad, hundreds of themes, designs or pictures might be evaluated (1573). ITL "will always check in at some point with the consumer on a final execution before we put it out on the market" (1574). "The script and the font of every word in every ad is all done by design. It's all researched very, very closely" (1615). For ads of new products with the necessary objective of creating brand awareness, "we would also try to measure, as best we can, what it is the consumers understand that the brand is offering and how the brand is unique from other brands in the market" (1579).

Before any ad is deployed in the marketplace, it is approved by ITL senior management at three levels: within the communications group, then by the marketing committee, and the management committee, the most senior of executives (1575). The management committee requires detailed information from the marketing staff, such as that from Project Image, as well as feasibility information from operations people about the equipment required, lead times, investments needed, and so on (1468). The two stages of approval from them are for development activities and deployment, also described as approval of the "idea" and the "on-market activity" (1470). After management approval is won, the project is presented to the "executional whips" for implementation planning details within their jurisdictions (for example, a communications plan for advertising that outlines the budgets, media mix and scheduling, message strategies, trade promotions, sales force training, PR activities) (1552).

\section{DEVELOPING PLAYER'S PREMIERE The irritation issue}

Player's Premiere was developed by ITL to meet the expressed consumer desire for a full flavour cigarette that was less irritating. The Broad Strokes 1992 document included conclusions about various unmet "consumer product needs". Reduced irritation was selected for development because "for years consumers have been telling us that that's an improvement that they would very much like in their product" (1518).

\section{Which comes first: the product or the promise?}

In elaborating upon this developmental task, Ricard testified: "There were really two [2] very, very key challenges here: one is communicating ...well, I guess, first of all, one was actually solving . . actually coming up with a product that actually delivered what it is that consumers were looking for; and secondly, finding a way to actually communicate that we had done that to the consumers" (1639). * For ITL, an objective was to offer a product that was seen as innovative. "It was important to say to consumers that we had been able to do something that had never been done before, and that is to maintain a high level of taste while at the same time reducing the harshness or the irritation associated with the product ... And so there was a big challenge to communicate to people that it actually had been done and that they should try it for themselves to prove to themselves that it had been done" (1640).

*All punctuation, including ellipses, appears in the court transcripts, capturing to some degree Ricard's "tell", his momentary restatements and awkwardness which provoked the lead author's curiosity.
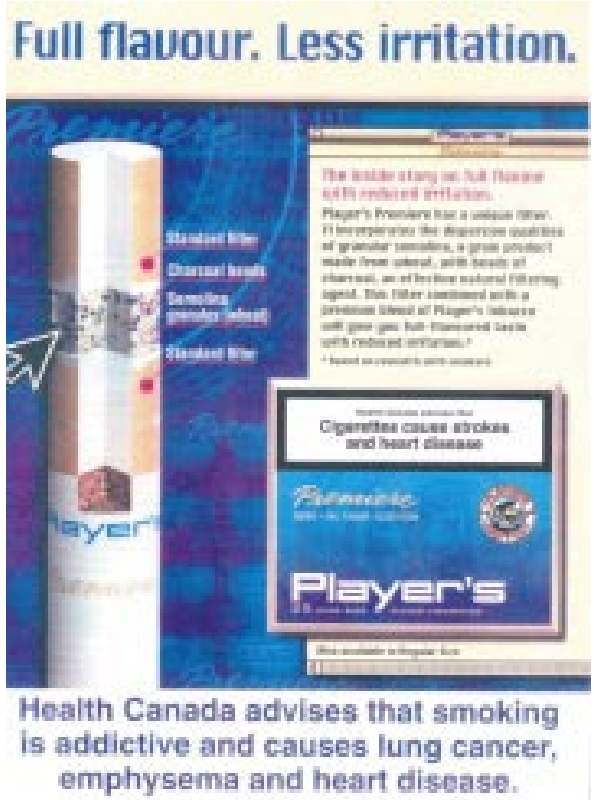

Figure 3 Player's Premiere Ad. "Full flavour. Less irritation" (Canada 1997).

\section{Crafting the image of scientific accomplishment}

The French language promotional execution became trial exhibit P-61, and the English version is shown in fig 3. There are obvious allusions to technology with the use of a cut-away style drawing of the cigarette filter and reference to its several constituents. The blueprint background was chosen "to create the impression of a craftsman or a draft[ing] table, or that somebody [sic] who's working with the science involved in developing new ideas and new things and all of that ... to bring in the notion of technology and engineering" (1643). In addition, the arrow that points to the middle of the filter was intentionally like one commonly seen on a computer screen, and "the package itself is presented in a way that it looks like an icon on a computer screen", such as a Microsoft Window, as is the text presenting "the inside story". The rationale for the visual reference to computers and blueprints is that it alludes to "new technology, and it speaks to being able to do things that we've never been able to do before" (1644-45). The ad copy mentions less or reduced irritation repeatedly, indicating that the claim is based on research, and refers to the "unique filter" with "dispersion qualities of granular semolina" and "beads of charcoal. An effective natural filtering agent". Reiterating, these design elements "bring in the notions of . . . a hi-tech approach that we've made this new discovery and that we have a new filter and that it is, in fact, this new filter which is giving you the product characteristics you've been looking for" (1644). The same graphic elements also appeared on special in-store displays, featuring three dimensional, oversized cut-away depictions of the filter.

To convey flavour tastefulness, ITL used "colours that were fairly dark and fairly rich" (1641). They also relied on the Player's Hero, the sailor featured on the cigarette package, because of "the ruggedness, and the independence, and self-reliance required to live this very rugged life at sea" (1641). The parent Player's brand also provided associations of tradition, heritage, and master craftsmanship. The name Premiere was used to convey "that this is a first, that this had never been done before" (1642). In addition, we note, Premiere is understood by both French and English audiences, an important consideration in bilingual Canada. 


\section{Honest advertising or "bullshit"?}

According to Ricard, "for a new brand to become successful, consumers will have to become aware that the brand exists ... [and] they have to know what does that brand have to offer that's different ... And again, advertising is really a very good means in which [sic], for us to be able to communicate accurately to consumers" (1527). Player's Premiere was fully launched in the spring of 1997, but did not achieve target sales volumes, then or later. "It never got off the ground, essentially" (1529). ITL blamed advertising regulations-more specifically, the implementation of the Tobacco Act-for the failure of Player's Premiere.

Filings by the Attorney General of Canada had included opinion that "almost nothing that is honest, factual, and fully disclosing can be construed into a positive selling message . . Their advertising instead has relied on pictures of health and images of intelligence and has misled consumers into believing filtered products in general, and low tar products in specific, to be safer than other forms, without knowing exactly why" ${ }^{\prime 17}$ This was also described, as visualised in an editorial cartoon (fig 4), as cultivating consumers just as farmers cultivate mushrooms: "Keep them in the dark and feed them lots of bullshit".

The finale of Ricard's testimony was to state that the success of his firm had come about by "fully and completely understanding what it is that consumers are looking for, how it is exactly that they perceive the various brands on the market, and by telling them specifically what it is that they will be getting from our products. And it's the fact that we deliver on the claim that has had us grow our market share" (1699). Continuing, he indignantly said: "I take very serious exception to that [bullshit statement] ... [It is] our ability to be able to develop products and communicate them honestly and straightforwardly, exactly what it is that they can expect, that has allowed us to grow our market share" (1700).



Figure 4 Cultivating smokers is like growing mushrooms. (Tim Rotheisler, Calgary Herald, with permission.)

\section{THE DOCUMENTARY EVIDENCE}

Several internal industry documents regarding the development of Player's Premiere were produced in pre-trial proceedings. One large file contained a chronological collection of reports, position papers, memos, etc. This became evidence in toto, with parenthetical notations below giving the last few digits of the trial's Bates page numbers. ${ }^{18}$ Interestingly, the industry documents about the development of Player's Premiere were not the subject of attention in the Crown's original case, and was not discussed in either the expert report on advertising or on packaging. ${ }^{19}{ }^{20}$ The documents were given consideration only because the industry offered Player's Premiere as an example to make their argument that the regulation of advertising was dysfunctional, preventing meaningful product improvements from being successfully marketed. The ITL documents were examined to assess the validity of the industry's assertions that:

(1) The product development preceded the development of the promotional promises

(2) Player's Premiere was indeed a new and improved product, with real differences in irritation levels (that is, "nothing to do with an illusion")

(3) The communications about Premiere were informative, honest and accurate

(4) The failure of Premiere was due to regulatory restraints on its advertising.

\section{Project Tomahawk: attacking the irritation issue}

The brand planning process for Player's Premiere was initially identified as Project Tomahawk. The Tomahawk Position Paper (August 1993) stated that "the greatest unsatisfied product need in the market place today is a universal need for reduced irritation" ( . .1359). Of the many smokers dissatisfied with their cigarettes in the preceding four years, "the vast majority, 63\% and growing, are looking for less irritation" ( . . .1361). ITL's measure of the degree of dissatisfaction was the discrepancy between ratings of "own" brand versus each respondent's "ideal" brand. The discrepancy for irritation was about twice that for the next most important expressed concern, "strength" (consumers on average wanting less strength), and more than three times any of the other measured concerns. "Healthfulness" was not measured directly, with "irritation" the only proximate dimension ( ...1369). Research with focus groups was initiated in August 1993 to determine "which possible approach[es] will, in consumers eyes, best meet the above objective", that is positioning a brand as medium strength with reduced irritation ( ...1342).

By October 1993, Project Tomahawk: Position Paper \#2 clarified what physical symptoms cause consumers concern for "harshness and irritation. In essence they are talking about a burning or discomfort on the back of the throat that occurs while smoking and, in some cases, the way the throat feels the morning after a night of heavy smoking" ( . . 1328). "The terms 'harshness' and 'irritation' are used synonymously" ( . . 1329). This research indicated "a need for real product improvement" ( . . 1332). In the search for this real product improvement, however, "actual tar and nicotine deliveries should not be a constraining factor at this time" ( . .1333).

Finding the right package, words, and gimmick Before an actual product improvement was found, a second wave of consumer research was initiated "to look at promotional packaging and/or merchandising options that will support the desired positioning" ( . .1333), and to determine the "credibility of different concepts in producing a smooth cigarette" ( . . 1335). The memo reporting on Wave II research noted that an ad claim of "naturally mellowed" had the advantage of minimising counter-argumentation. "Subtle and low-key, the statement about a process does not appear to arouse the usual cynicism and guilt that we normally see when cigarette companies talk about natural ingredients" ( . . 1307). In January 1994, Position Paper \#3 indicated that 
they had gained "greater understanding of consumer vocabulary" ( . . 1293). "In the next round of research we will more fully explore unique or novel product characteristics and what role this can play in providing credibility to the claim that this product is superior to all the others" ( . .1299). While perception management was being perfected, however, it was acknowledged that "the greatest challenge will be to actually deliver on the promise" ( . .1294). In March 1994, this was echoed by a research supplier noting: "What remains to be done, in our view, and what is essential to the success of the Tomahawk proposition, is to develop the product that fully delivers on the promise that we are about to make to consum$\operatorname{ers}^{\prime \prime}(\ldots 1379){ }^{21}$

\section{Interim actions: imagery $\mathbf{v}$ reality}

A year later, in March 1995, after nearly two years of effort, ITL had not yet found a satisfactory product to deliver on the increasingly well crafted promise of less irritation. At this time, rival RJR-Macdonald's Export 'A' Medium was doing particularly well among those under 25 years old in Quebec. ${ }^{22-24}$ To respond to this, ITL started Project Interim Tomahawk- "interim" because a truly "less irritating" product was not yet a fact. Marketing efforts proceeded in faith that "this one can be driven by imagery rather than significant product differences" ( . . 1270). The illusion of a product improvement, even if not better in fact, would now suffice for ITL.

Product based research and development (R\&D)

In April 1995, emails continued to express "major disappointment" with the product version then under test for Project Tomahawk. In June 1995, a memo reported on meetings with a representative from Baumgartner, a filter manufacturer based in Switzerland and the USA, regarding the CR-20 filter, with a cavity containing a mix of active ingredients such as carbon and inert ballast. This cavity type of filter, like the Caviflex ultimately selected, had been in use in other jurisdictions, allowing for the parent firm, BAT, to have relevant information ( . . 1247). ITL noted that filters "constructed in this way are somewhat cheaper because the ballast can be inexpensive and filter making machines can run at higher speeds" ( . .1250). As seen in the trade advertisement (fig 5), the filter manufacturer does not push the implied healthfulness of "less irritation" in selling this filter to tobacco firms. The cavity filter offers flexibility and this ad reminds cigarette firms that the Caviflex technology gives them the trade-off choice of "increased performance" or "cost reduction". "It's simply the question of ingredient mix ... the secret is in the cavity".

\section{Technology provides "tangible credibility"}

Tomahawk Position Paper \#4, November 1995, reported that the multiple waves of consumer research "make sure we will be ready when the product itself is ready" ( . .1233). The product "concept" had by this time been amended to include: "technology is credited with the ability to deliver such a product" ( . . 1236). Perhaps the most important characteristic of the "specialty gap filter" was that it looked different and impressive to the lay smoker, so that it "could be used as a communications tool" ( . .1238).

The objective of creating a truly "less irritating" cigarette remained unmet, however. "Tomahawk requires a product that delivers noticeably improved product characteristics as it relates to taste and irritation levels" ( . .1238, emphasis in original). The ideal product would be different in both appearance and actuality. The appearance would shape consumer expectations, provoking curiosity and trial, and the actual smoking experience would lead to product satisfaction and repeat purchasing.



\section{It's your move.}

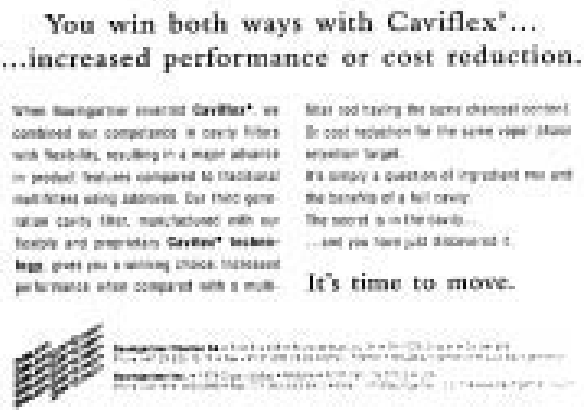

Figure 5 Baumgartner (Caviflex) Ad. "It's your move" (Tobacco Reporter 2002;129:49).

\section{Rushing to test the total offer}

In May 1996, a Total Offer Research Brief stated: "Project Tomahawk is at a stage where much of the necessary development work with respect to concept articulation . . . and packaging is now complete. What is less complete, however, is the product" ( . . 1201). Nonetheless, ITL was impatient. "[I]t is imperative that all possible alternatives for Tomahawk be examined in light of a potential launch date within the 1996 year" (. . .1201). Consumer testing proceeded with "mocked-up in-store communications, as well as mocked up pamphlets that are designed to replicate the content, if not the form of the eventual pack inserts". Also mocked-up were "the final packaging design, including a standard version as well as an equal number of the promotional 'glow-in-the-dark' packaging" using phosphorescent lettering ( . .1204).

By 26 June 1996, research "results have led to a decision to launch with the Caviflex option" ( . . 1193). The Interim Tomahawk Creative Brief called for yet another wave of consumer research as the "last chance to test and fine tune the communication material" before the planned launch date of mid October ( . .1193). The anticipated communications mix included a cigarette package insert, a take-away leaflet, outdoor, transit and print ads, in-store counter displays, and wood box matches. Trade communications activities were similarly thorough. Because ITL was aware of the "interim" and still inferior nature of the product to be launched, the research agenda also sought to "find out what their reactions would be if in a year or two, we would come up with a new and improved version" ( . .1188). "High interest/high trial during the initial weeks of launch" were expected because previous research results had been "extremely positive" ( . .1188). The thoroughness and many steps in this long chain of consumer research about the promotional promise can be seen in table 1 .

\section{Progress to date and plans}

A memo summarised the physical product development in four steps. First, existing products were examined to "determine the most appropriate cigarette design that would provide the best balance and the best mechanics" ( . .1182). 
Table 1 Chronology of communications research for Player's Premiere

Project Image (August 1993 and earlier)

- Confirmed the greatest unmet consumer need was a product with "reduced irritation"

Tomahawk Wave I (September 1993)

- Defined the ideal cigarette properties

- Determined the most suitable trademark(s) as a platform

- Explored initial concepts best suited for communicating the positioning

Tomahawk Wave II (November 1993)

- Gained direction of the appropriate vocabulary to use

- Gained direction of potential qualifiers (brand names)

- Gained direction of potential concept statements

- Obtained a more in-depth knowledge of appropriate product characteristics

- Gained direction on identifying the most effective package designs

Tomahawk Wave III (March 1994)

- Gained an understanding of further refinements to the results of previous waves

- Examined "support" features, but none provided "tangible credibility"

- Gained an understanding of the acceptance of foreign tobacco to enhance smoothness

Tomahawk IV (Interim Tomahawk) (April 1995)

- Understand the success of the competitive Export Medium brand in Quebec

- Reconfirmed that Tomahawk is the answer

-to Export Medium's challenge, and

-to the need for a cigarette with improved taste to irritation ratio

Tomahawk V (December 1995)

- Determined which product elements best deliver perceived product attributes

- Determined the most effective combination of communication elements (packaging, qualifiers, concep statements)

Interim Tomahawk Research (May 1996)

- Understand contribution of the Caviflex filter to believability of the concept

- Identified concerns consumer might have regarding Caviflex filter

- Determined if communication needed about the contents of the filter chamber

- Verified that learning re: CR-20 filter holds true

- Studied the effective method for delivering the identified message

Interim Tomahawk Total Offer Research (June 1996)

- Assessed consumer reaction to three different concepts

- Assessed consumer perceptions "from a suggested imagery" perspective

- Evaluated how perceptions change at varying levels of exposure

- Determined reactions to a promotional package with phosphorescent lettering

Interim Tomahawk Research (July 1996)

- Examined the finalised communications strategy

- Sought a full understanding of consumers' interpretations from the communications

- Fine tuned communication message re: Caviflex filter.

- Determined if consumer perceived the Caviflex concept as healthier

- Explored reactions to a "new and improved" Tomahawk in the future

- Sought to understand why some consumers reject the concept totally

Post Launch Assessment (January 1997)

- Does Player's Premiere (PP) effect the Player's trademark negatively?

- Does PP have an impact on the fibreglass rumour?

- Do consumers understand PP?

- How and where did consumers get the message about the filter?

- Does Premiere deliver on its promise?

Tomahawk Retail Survey (March 1997

- Understand which trade focused activities are most effective

- Do retailers comprehend the Premiere concept?

Bar Promotion/Research (April 1997)

- Awareness of new cigarette products

- Recall of means of awareness

- Recall of Premiere's uniqueness

- Understand role of word-of-mouth

Source Documents (all within D-237a):

Tomahawk Research Brief Wave V, December 1995 ( . . 1217-8)

Interim Tomahawk Research Brief, May 1996 ( . . . 1210)

Interim Tomahawk Total Offer Test, Research Brief, May 1996 ( . . . 1202

Interim Tomahawk Research Brief, July 1996 ( . . . 1178)

Interim Tomahawk Research Brief, August 1996 ( . . . 1174)

Interim Tomahawk Research Brief, December 1996 ( . . .1124)

Tomahawk Bar Promotion Research, March 1997 ( . . . 1 104-5)

Tomahawk Retail Survey, March 1997 ( . . . 1091) 
Second, over 50 recipes were studied, including both conventional recipes and experimental blends. Third, various means of "reducing apparent irritation [whether real of perceived] through filtration were assessed. Consumer data shows that a claimed decrease of irritation is likely to be more believed with a visual difference" ( . .1183). Several types of filters were studied (for example, CR-20 resin cavity filter, double density filter, a carbon paper filter), with data on aldehyde yields measured in both internal studies and by filter suppliers. Among those tested, "the cavity filter is found to be the best short term alternative for Tomahawk" even though "internal evaluations do not indicate a reduction in aldehydes" ( . .1183). Other potential means of reducing irritation, such as increasing density, using additional additives and flavours ( $\mathrm{HCl}, \mathrm{NH}_{4} \mathrm{Cl}$, acids, ethyl esters), increasing moisture, considering the tobacco cut per inch, and incorporating specialty papers (glycerin, low $\mathrm{PH}$ coated, wood pulp, $\mathrm{CaCO}_{3}$, and nitrate), were also evaluated, "but none of the samples tested provided the desired effect" ( ...1183).

The fourth step was "quantitative consumer evaluation" in taste panels. The results were not encouraging for the King Size version as "the cavity filter tends to have more impact and irritation" than the competitive standard employed. The regular length delivered more (not less) tar, nicotine, and carbon monoxide ( $\mathrm{CO}$ ) than either of the two competitive standards used. Even interpreted optimistically, these findings indicated "product similarity relative to opposition. However the total offer [combination filter/recipe]might be more relevant to [the] consumer since the filter has a greater potential to reduce perceived irritation" ( ...1184, emphases added).

The Interim Tomahawk Research Brief of July 1996 considered whether consumers would perceive this product as healthier, albeit expressed in coded language: "Understand what elements of the Caviflex concept might lead consumers to believe it is a DAY product" ( . .1179). This refers to earlier research efforts by ITL, using the code name Project DAY, to develop a product that would have "lower biological activity" (presumably carcinogenesis) and be accepted by consumers as "better for you" and a "safer smoking experience". ${ }^{25}$ On 1 August 1996, the Project Tomahawk Work Plan at long last called for a review of the literature on the charcoal filters already committed to ( ..1176).

\section{Seeking and getting management approval}

In drafting the final recommendation regarding Tomahawk on 11 September 1996, the decision criteria were specified as: (1) delivering a "significant improvement", (2) being consistent with trademark positioning, (3) communicating the "right things to consumers", (4) production feasibility, and (5) anticipated profit. The success criteria for the test markets were "no damage on trademark perception" and realising a modest one-half of $1 \%$ market share, with allowance for $80 \%$ of that to be cannibalism, the taking of sales away from other ITL brands, yielding a net new share growth of just one tenth of $1 \%(\ldots 1152)$. Production was not seen as a problem as "BAT has been using a similar filter for the last 20 years". The official recommendation was to proceed, based on faith in the deceptive potential of the advertising: "We have solid evidence that [the] image and communication behind the product are very strong ... and the image associated with it could carry on the project at its optimum potential" ( . .1158).

The management committee endorsed this and literally gave its anticipated official stamp of approval on 16 September 1996. This formally authorised test markets in three Canadian coastal provinces: British Columbia, Nova Scotia, and Prince Edward Island. National launch into the remaining seven provinces was set for 1 April 1997, assuming test market results were consistent with "the positive results in research" $(\ldots 1151)$
Questions and answers for sales personnel

ITL prepared a series of "Possible questions \& appropriate answers" for sales personnel located in the test market regions ( . . 1130-6). Unlike in the consumer ad (fig 3), here the "unique filter" claim was qualified as applying "in Canada". When asked if Premiere outperformed competitive products, the sales force were instructed to respond: "I'm happy to say that it did". No additional information was provided (or is now evident) to buttress this claim, however. Nowhere in the seven pages of Q\&A is "irritation" explained, nor how it was supposedly reduced, nor the extent to which Premiere realised reductions. This failure to inform the sales force, retailers or consumers occurred despite the fact that draft questions included both "What is irritation?" and "What causes irritation?" ( . . 1167). In a 3 February 1997 letter from the sales director to his retail clients, a vague explanation was offered that the "reduced irritation results from a combination of a unique filter and a premium blend of Player's tobacco" $(\ldots .0993) .{ }^{27}$

\section{Irritating test market results}

In addition to monitoring sales through syndicated services, the test market was the site of yet another round of consumer research. In January 1997, when consumers reported whether their own experience was of less or more irritation, only $18 \%$ of those who normally smoked mid-light strength products reported less irritation. As seen in table 2, the results from those who normally smoked a stronger cigarette were even more discouraging. Only 15\% of these research participants reported less irritation, well outnumbered by the $24 \%$ who reported more irritation. The majority of respondents reported no observable difference. This failure to deliver on the "reduced irritation" promise was not explored further within this report, in stark contrast to the 10 tables and two-and-ahalf pages dealing with ITL's concerns about a rumour of fibreglass contamination ( ..1120-2).

\begin{tabular}{|c|c|c|}
\hline $\begin{array}{l}\text { Total (British } \\
\text { Columbia and } \\
\text { Nova Scotia) }\end{array}$ & $\begin{array}{l}\text { Medium and } \\
\text { above* }\end{array}$ & $\begin{array}{l}\text { Mid light } \\
\text { and below* }\end{array}$ \\
\hline Less irritation & $15 \%$ & $18 \%$ \\
\hline More irritation & $24 \%$ & $18 \%$ \\
\hline No difference & $53 \%$ & $56 \%$ \\
\hline
\end{tabular}

Consumers curious, but left in the dark

Focus groups during January 1997 indicated that Premiere communications generated "considerable curiosity", stemming especially from the in-store 3-D display. ${ }^{28}$ While consumers understood the offer to be "a unique filter providing reduced irritation and full flavour", consumers were not very enlightened and wanted more information: "Some of the terminology in the print materials is not always meaningful . . .there is a desire for a more precise explanation of how the filter actually reduces irritation". There was also speculation by a minority of subjects "regarding possible health related advantages attributable to the new filter ... [inferring] that if a new filter removes something that other filters do not, it is inherently less detrimental" ( . .1031).

This was consistent with the observation that "the filter dominates consumer playback", overshadowing other elements. When consumers discussed health related inferences, "being less harmful, not as bad or better for you are the types of phrases used ... When asked to explain ... .being less irritating to the throat or lungs or being smoother is frequently 
played back" ( . . 1042). When asked about "'something' being removed, it is usually not defined in any precise way, [but] a few make references to toxins and some ... anticipate lower tar or nicotine" ( . . 1043). The report also notes that the role of charcoal in the filter is not clear, even though some subjects did associate it with fish tanks and water filters. Moreover, "'dispersion qualities' is not a consumer friendly term and is not always understood or meaningful" ( . . 1045).

Communications with multi-media intensity

For the national launch of Player's Premiere, The Project Tomahawk Communication Plan, March 1997, identified the role of communication as twofold-providing information, and shaping perceptions. It was unambiguously stated that "Emphasis on filter = credibility of the concept" (p 7). The media plan to generate awareness and convert this to product trial included an expanded variety of media: billboards, transit shelters, bus sides, newspapers (sports and entertainment sections), university papers, magazines (music, TV, sports), ethnic publications, underground publications, direct marketing, and leaflets. The in-store floor and counter displays featured a cut-away rendering of the filter. Also used were flyers, matches, brochures, easel cards, shelf talkers with arrows, shelf strips, pack risers, pack slide flaps with concept message, and vending machine strips. Distribution and exposure to promotional communications occurred not only in mass media and the normal tobacco retail channels, but also in bars, on coffee trucks (canteens), via a 1-800 (toll-free) telephone number, and in a direct mailing of letters and brochures to Player's smokers in ITL's database. ${ }^{29}$

\section{More irritating results}

ITL received more bad news in March 1997. For those trying the product, but unaware of the Premiere concept of the "unique" filter, the number of consumers reporting more irritation outnumbered those reporting less irritation by nearly three to one $(29 \% v 10 \%)$. As can be seen in table 3, however, "if a consumer has an awareness of the concept it biases the perceptions of smokers in Premiere's favor as far as irritation is concerned" $(\ldots 1100)$. This Tomahawk progress report was very widely circulated up and down the management chain to reach all members of the senior executive management committee and marketing committee, as well as the junior executives and staff working on market research, strategy, and communications (...1103).

An update on 15 May 1997 was no more encouraging. After 17 weeks on the market, with the extensive communications effort, sales did not meet expectations. Ultimately, after lingering in the market for four years, Premiere was withdrawn from the marketplace in 2001.

Table 3 Irritation perception by concept awareness (March 1997)

\begin{tabular}{lll}
\hline Perceived & Unaware* & Aware* \\
\hline Less irritation & $10 \%$ & $40 \%$ \\
More irritation & $29 \%$ & $33 \%$ \\
No difference & $47 \%$ & $21 \%$ \\
\hline
\end{tabular}

*Sums are less than $100 \%$, presumably because of non-response.

\section{DISCUSSION}

\section{Did the product precede the promise?}

No. Unmistakably, the development of the Player's Premiere product did not precede that of the promotional promise. It is clear that the research effort honing the promotional promise was underway right from the very beginning, with three waves completed within the first year. These and subsequent efforts revised and refined the communication of the "less irritation" promise through research on the product qualifiers, packaging, advertising wording and imagery, retail displays, etc (table 1).

\section{Was there "less irritation" as promised?}

No. Despite repeated recognition within ITL documents that "what is essential to the success of the Tomahawk proposition, is to develop the product that fully delivers on the promise", the product marketed was not in fact "less irritating". Indeed, it was demonstrably inferior rather than new and improved. Only a small proportion of triers reported it to be "less irritating" as promised, while a larger proportion found it "more irritating" and many felt no difference.

Reports to the provincial government of British Columbia in March 2000 for Player's Premiere and Player's Light King Size revealed that Premiere delivered significantly higher yields of several irritants and other chemicals such as ammonia, acetaldehyde, hydrogen cyanide, phenol, and both tar and nicotine. ${ }^{30}$ This sort of data, along with that disclosed in internal reports such as a Project Tomahawk Table of Aldehydes (1996), were summarised in an expert report. ITL saw respiratory irritation of main and sidestream smoke as a function of the "known irritants" of formaldehyde, acetaldehyde, acrolein, propionaldehyde, acetone, and ammonia. The expert report concluded:

"Our analysis of all of the documents furnished by the Attorney General of Canada shows that the mainstream smoke of the Player's Premiere cigarette contains even greater quantities of irritating substances than the smoke of the Player's Light Smooth Regular and of the Player's Light Regular". ${ }^{31}$

\section{ITL's motivations and efforts}

Reduced irritation was identified as far and away the most significant unmet consumer need, and therefore represented a potentially large market opportunity. Management and R\&D had previously struggled with the irritation issue in developing Player's Smooth, a brand launched in 1992. Adding to that experience, ITL invested at least another three-and-a-half years of R\&D toward Player's Premiere, from early 1993 to late 1996, far more than the typical "two years to go from an idea to something we can actually put on this market" (1457). The development of both Player's Smooth (Project Trident) and Player's Premiere (Project Tomahawk) explored a variety of technological tactics to achieve less irritation without sacrificing taste, such as varieties of blends, filters, paper chemistry, additives, and flavourings.

Additional motives and goals for product development existed, however, such as the credibility of the new product claims, the enduring trademark reputation, and cost savings/ profitability. The use of the Caviflex filter with charcoal was obviously not motivated solely by its technological efficacy, if at all, as it was decided upon before a literature review on the efficacy of charcoal filters was even initiated. We know that this type of filter was liked by management, even though ineffective, because it provided the much desired "tangible credibility". While "the cavity filter is . . a means to reduce apparent irritation through filtration ... internal evaluations do not indicate a reduction in aldehydes" ( . .1183, emphasis added). Highlights of the tension between producing real or imagineered + reduced irritation can be seen in table 4 . Recall that the Caviflex filter chosen for Premiere is sold to manufacturers as providing a trade-off of "increased performance" or

†lmagineering is a Disney term coined long ago for designing compelling illusions. 
Table 4 Real versus "imagineered" reduced irritation (Player's Premiere)

\begin{tabular}{|c|c|c|}
\hline Date & Source & Statement \\
\hline October 1993 & Position Paper \#2, p 5 & Consumers have "a need for real product improvement" \\
\hline January 1994 & Position Paper \#3, p 2 & "[T] he greatest challenge will be to actually deliver on the promise" \\
\hline January 1994 & Position Paper \#3, p 9 & "[T] he product must in the very least deliver on our promise" \\
\hline March 1994 & Phase III Research Results, p 5 & None of the "novel product features ... appeared to add any tangible credibility" \\
\hline March 1994 & Phase III Research Results, p 5 & $\begin{array}{l}\text { "What remains to be done, in our view, and what is essential to the success of the } \\
\text { Tomahawk proposition, is to develop the product that fully delivers on the promise that we } \\
\text { are about to make to consumers" }\end{array}$ \\
\hline March 1995 & Interim Tomahawk Position Paper \# 1, p 5 & $\begin{array}{l}\text { Interim Tomahawk "can be driven by imagery rather than significant product } \\
\text { differences" }\end{array}$ \\
\hline November 1995 & Position Paper \#4, p 3 & "Tomahawk requires a product that delivers noticeably improved product characteristics" \\
\hline November 1995 & Position Paper \#4, p 5 & The "specialty gap filter . . could be used as a communications tool" \\
\hline November 1995 & Position Paper \#4, p 3 & "[T]echnology is credited with the ability to deliver such a product" \\
\hline May 1996 & Total Offer Test Research Brief, p 1 & "What is less complete, however, is the product" \\
\hline March 1997 & Communications Plan, $\mathrm{p} 7$ & "Emphasis on filter = credibility of the concept" \\
\hline January 2001 & Ricard interrogatory, p 81 & $\begin{array}{l}\text { "We want to give them information to understand how one brand is different than another } \\
\text { on key attributes" }\end{array}$ \\
\hline January 2002 & Ricard testimony, p 1615 & $\begin{array}{l}\text { "The script and the font of every word in every ad is all done by design. It's all researched } \\
\text { very, very closely" }\end{array}$ \\
\hline
\end{tabular}

"cost reduction". Since Player's Premiere did not realise any increased performance in reducing irritation, perhaps the dominant goal was cost reduction.

\section{Was the advertising informative?}

No. While the ad style of fig 3 may at first glance seem more informative than other types of cigarette ads, such as those portraying Marlboro Country, the information presented is clearly limited and vague. The ad copy explaining the cut-away drawing mentions "charcoal beads" and "the dispersion qualities of semolina", but research feedback showed ITL that consumers were puzzled by this terminology and the lack of any explanation.

Internal documents noted that "we must inform smokers of the Caviflex filter - both its contents and how it works". Smokers were not informed about the performance of the Caviflex filter, however. Rather, the ads were left intentionally ambiguous, and did not provide any factual information about what smoke constituents caused irritation, nor what the filter did to reduce or remove smoke constituents, nor how this product compared to other brands, nor what degree of improvement might be expected, cf half the calories.

This is not because the matter is too complex for smokers to grasp, as conveying the meaning of technical terms is easily done in advertising copy, and "unlike some hard-to-learn method, explanatory context is amazingly simple". ${ }^{32}$ Leaving the ad intentionally ambiguous encourages consumers to infer meanings of scientific accomplishment and associated reductions in health risks. As research reports noted, an expected inference is that "if a new filter removes something that other filters do not, it is inherently less detrimental".

Instead of informative explication, the ads relied upon the repeatedly researched associative imagery of computer graphics, blueprint tonality, etc. Most centrally, the ads relied on the cavity filter, depicted in cut-away renderings. The description of this filter as "unique" suggested a breakthrough new technology, even though similar filters already existed in other jurisdictions, in some cases for at least 20 years.

\section{Bullshit and ruses: "a massive marketing ploy"}

The use of the filter's appearance to gain unwarranted "tangible credibility" was described as a "gimmick" in trial testimony, for which the trial judge volunteered the French translation of "ruse". It is clearly not consistent with ITL's claim to "develop products and communicate them honestly and straightforwardly" and to inform consumers. This gimmick, or ruse, might also be termed a gambit, device, stratagem, artifice, contrivance, trick, scam or fraud. In the trial court's judgment upholding the constitutionality of Canada's Tobacco Act, it was described as "nothing more than a massive marketing ploy" (table 5). The evidence is clearly consistent with the mushroom model of consumer cultivation mentioned earlier, with its crude but apt analogy of cigarette advertising to bullshit. Whether the language is polite or crude, English or French, as Shakespeare might have said, a ruse by any other name would smell as foul.

\section{Advertising effectiveness}

The total communications mix employed by ITL generated "considerable curiosity", relatively high degrees of general awareness of the presence of "a unique filter" (even if little understanding of how, why, and to what extent it worked), and precipitated consumer trial. Significantly, the promotional communication also influenced some users' judgments about product performance, apparently convincing about 30\% of users who might otherwise have reported no difference to report less irritation (table 3 ). Even greater awareness of the filter and impact on perceptions might have been realised had ITL not cancelled a planned package insert. Despite their effectiveness demonstrated in testing, package inserts were cancelled on 15 October 1996 when federal regulation was being contemplated to mandate inserts as a health risk communication tool. Management apparently felt it was not the time, politically, to demonstrate the feasibility and effectiveness of package inserts.

\section{Advertising regulation and product failure}

Given the intensity of communications in many media, and the proven success in generating curiosity, it is highly unlikely that the product failed because of advertising restraints. There was a window of promotional opportunity between the time the previous law, the Tobacco Products Control Act, was judged unconstitutional and the enactment of the replacement Tobacco Act. This may have influenced the timing of the Premiere product launch, but ITL had already spent many years working on the irritation problem for both Premiere and its predecessor, Player's Smooth. The test markets for Premiere had many months of unfettered promotional activity, and still did not perform well. Moreover, the Tobacco Act continues to allow informative messages. Complying with the new law in 1997 would have meant removal of lifestyle elements like the blueprint and computer imagery, but text based notices to consumers of a new product that was less irritating could have persisted.

A far more probable explanation for the product's failure in the marketplace is the fact that the product simply did not live 
Table 5 The trial court's judgment (highlights re: Premiere)

[124] Imperial Tobacco launched its Premiere brand claiming it was less irritating to the throat, but Mr. Ricard cannot explain how this was so because

I.T.L. commissioned no medical or scientific studies to back its claims

[215] The introduction of Player's Premiere is a mere advertising ploy. There is no scientific evidence supporting the notion that the brand is less irritating to smokers' throats. Three years after its introduction, we are still trying to figure out the nature of the magic tobacco formula trumpeted at the launch of this brand of cigarette

[216] The same is true of the so-called special filters specific to Premiere-brand cigarettes, which are in no way different from the filters that have been in use for years. As is the case with all carbon filters, the industry is unable to say precisely how they are more effective

[237] The launch of the Player's Premiere brand of cigarettes, supposedly less irritating to the throat, is nothing more than a massive marketing ploy that ... is no different from ordinary cigarettes

[528] Fact: the supposedly less-irritating cigarette is merely the creation of a tobacco company's marketing department; filters allow every single carcinogenic gas contained in cigarette smoke to pass through; and there is no such thing as a "light" or "healthier" cigarette

Judge André Denis, Superior Court of Quebec.

Decision in JTI-Macdonald et al vs. AG of Canada, December 2002.

up to its promotional promise. Promotional communication can stimulate curiosity and product trial, but if that trial violates consumer expectations, it is extremely unlikely that consumers will be satisfied, converted to regular users, or motivated to tell friends about it. As the very first Tomahawk position paper stated: "The bottom line with consumers was that they would try the product and judge for themselves whether it lived up to its claim" (1363-4). As is often remarked among marketing professionals, the fastest way to kill a bad product is with good advertising.

Does advertising regulation reduce the industry's ability to successfully introduce a truly innovative, "new and improved" product? This case does not answer this question, despite being offered by the industry for this purpose, as Player's Premiere was definitely not superior to the other cigarette products with which it competed.

\section{A typical or unique case?}

Unfortunately, this case is more typical than unique. The dilemma of providing a milder, smoother, lighter smoke while maintaining consumer satisfaction with the total consumption experience is certainly a longstanding one, evident in the introduction of filters in the 1950s and "lights" in the 1970s. During the 1980s, the American firm, RJ Reynolds, repositioned its Camel brand to achieve perceived reductions in smoke harshness and irritation. ${ }^{33}$ The use of cut-away drawings, accompanied by ad claims of "unique" filtration, have also been evident over many years in many jurisdictions. Documents from other firms show the pattern of the promotional personality being chosen, and then products developed to suit, if possible. The strategy of Rothmans, Benson \& Hedges, an ITL rival, is to "think imagery/brand personality first and then develop the products with taste qualities/ product and package attributes that reinforce image $e^{\prime 34}$ Thus, this Premiere process and market offering does not seem idiosyncratic, but rather seems to reflect practices apparent for other brands, firms, and jurisdictions.

ITL's lawyers and executive chose Player's Premiere as a representative case for presentation to the court on behalf of the entire industry. It is implausible that they would intentionally choose the worst atypical example for this purpose. Presumably they chose their best case, but if this is either a typical or the best example the industry could present, one can only wonder in dismay about the merits of the new product projects in the rest of the industry.

\section{Scepticism needed about the industry's harm reduction products}

In choosing this Premiere case as their best foot to put forward, the industry tripped over themselves and inadvertently exposed themselves in the process, by calling careful

\section{What this paper adds}

Prior research has analysed internal tobacco industry documents to provide evidence of the marketing and research agendas of various tobacco manufacturers, including those relating to cigarette design and promotional campaigns during various historical periods. This paper examines industry executive testimony and newly admitted internal documents from the 1990s to gain insight into the more contemporary product development process as demonstrated by Canada's largest tobacco firm, Imperial Tobacco, a BAT and B\&W affiliate. The analysis reveals that their promotional promise of "reduced irritation" for Player's Premiere cigarettes was never in fact realised, despite much effort. This claim was likely to be falsely perceived by consumers and regulators as offering risk reduction. According to the trial court, however, this was "nothing more than a massive marketing ploy". Based on the deceptiveness of the industry advertising and executive testimony, as exposed by internal documents, new cigarette products that are portrayed as risk reduced should be treated with much scepticism.

attention to the Player's Premiere documents and development process. Once again in the 1990s we see that the cigarette industry has crafted a product to seem like a breakthrough technology with reduced health consequences. But while seemingly "new and improved", in fact, it was neither. The industry's innovation was solely a marketing ploy to gain sales or market share while providing no real consumer benefit, hence no possible public health benefit. Had Premiere been truly less irritating to smoke, even this would not necessarily imply any health benefit.

The representations about this product in the advertising, and also in the sworn court testimony, are demonstrated by the internal documents to have been deceptively vague and/or misleading. The Premiere case history shows the triumph of style over substance in this industry, an example that adds to the justification, both legal and moral, for severe limits on tobacco industry advertising.

Future new products that seem to be risk reduced should be treated with much scepticism, as should representations by the industry about these new products even if in official submissions to regulatory agencies or in sworn testimony to courts or legislative bodies. In a pretrial interrogatory, Ricard asserted: “The tobacco industry doesn't have any credibility in the eyes of consumers to speak on anything related to health or scientific matters" (p 72). To the extent that this statement is true, it is quite appropriate consumer scepticism. It is equally appropriate for the industry's credibility to be heavily discounted in the eyes of scholars, legislators and jurists. 


\section{ACKNOWLEDGEMENTS}

Document access was aided by the litigation team representing the federal government of Canada, led by Claude Joyal and Maurice Regnier.

\section{Authors' affiliations}

R W Pollay, Faculty of Commerce and Business Administration, University of British Columbia, Vancouver, BC, Canada

T Dewhirst, College of Commerce, University of Saskatchewan, Saskatoon, Saskatchewan, Canada

\section{REFERENCES}

1 Pollay RW. Filters, flavor . . f flim-flam, too!: cigarette advertising content and its regulation. Journal of Public Policy and Marketing 1989;8:30-9.

2 Pollay RW, Dewhirst T. The dark side of marketing seemingly "Light" cigarettes: successful images and failed fact. Tobacco Control 2002;11 (suppl I):i18-31.

3 Kozlowski LT, O'Connor RJ. Cigarette filter ventilation is a defective design because of misleading taste, bigger puffs, and blocked vents. Tobacco Control 2002;1 1 (suppl I):i40-50.

4 Canova D, Myers ML, Smith DE, et al. Changing the future of tobacco marketing by understanding the mistakes of the past: lessons from "Lights". Tobacco Control 2001;10 (suppl I): i43-4.

5 Pollay RW. Zebras in Russia! Where next? Tobacco Control 2003; 12:89-90

6 Slade J, Connolly GN, Lymperis D. Eclipse: does it live up to its health claims? Tobacco Control 2002;11 (suppl II):ii64-70.

7 Institute of Medicine. Clearing the smoke: assessing the science base for tobacco harm reduction. Washington DC: National Academy Press, 2001.

8 Pollay RW, Dewhirst T. A Premiere example of cigarette new product development and unfulfilled promises: bullshit and ruses. History of Advertising Archives, Faculty of Commerce, UBC, Working Paper 03.1, 34 pages.

9 Anon. The Tobacco Act, Statutes of Canada 1997, Ch. 13 (original). Ch. T11.5 (amended).

10 Testimony of Ed Ricard, in JTI-Macdonald Corp., Rothmans, Benson \& Hedges Inc. and Imperial Tobacco Ltd v. Attorney General of Canada and Canadian Cancer Society (intervener). Quebec Superior Court, Nos. 500-05-031299-975, 500-05-03 1306-974, 500-05-031332-978, Vol. 7 (23 January 2002), p 1278-485; Vol. 8 (24 January 2002), p $1495-713$

11 Ricard's job history was outlined in pretrial questioning Interrogatory of Ed Ricard (25 January 2001), Imperial Tobacco Ltd v. Attorney General of Canada, Quebec Superior Court (500-05-03 1332-974), p 15-7.

12 Aaker DA. Building strong brands. New York: The Free Press, 1996

13 Shapiro SJ, Wong K, Perreault WD, et al. Basic marketing: a global-managerial approach, 10th Canadian ed. Toronto, Ontario: McGraw-Hill Ryerson Ltd, 2002
14 Pollay RW, Lavack AM. The targeting of youths by cigarette marketers: archival evidence on trial. Advances in Consumer Research 1993;20:266-71

15 Dewhirst T, Sparks R. Intertextuality, tobacco sponsorship of sports, and adolescent male smoking culture: a selective review of tobacco industry documents. Journal of Sport and Social Issues (in press).

16 Anon. Non-user brand ratings - total smokers 19+, Project Image (Trial Exhibit P-42).

17 Pollay RW. How cigarette advertising works: rich imagery and poor information. Expert Report. (Trial Exhibit D-57). Toronto, Ontario: Ontario Tobacco Research Unit, Special Report Series, June 2002, 54 pages.

18 Project Tomahawk (Player's) 1993-1997. Trial Exhibit D-237a: Bates pages $99001064-1371$

19 Pollay RW. Trial Exhibit D-57. Op cit.

20 Pollay RW. The role of packaging seen through industry documents. Working Paper 01.4 (March 2001), Faculty of Commerce, University of British Columbia, 31 pages. Trial Exhibit D-116.

21 Project Tomahawk - Phase III Concept Development, Francophones, Final Report. Ad Hoc Marketing. 16 March 1994. Trial Exhibit D-237b: Bates pages $99001372-1427$

22 ITL market update. 25 April 1994. Trial Exhibit D-088: Bates pages 502596045-6055.

23 Pollay RW. Export "A" ads are extremely expert, eh? Tobacco Control $2001 ; 10: 71-4$

24 Dewhirst T. Male youth, extreme sports, and the gendering of smoking: a case study of Export " $A$ "TM brand marketing in Canada. In: Fuller L, ed. Sexual sports rhetoric globally. Binghamton, New York: Haworth Press (in press).

25 ITL Product Development Conference, Montreal. 22-24 August 1996 Trial Exhibit D-98: Bates page 201812599

26 ITL Broad Strokes 1994. Trial Exhibit D-86:14

27 Project Tomahawk national launch (sales file). Various dates. Trial Exhibit D-237c: Bates pages 99000989-1002.

28 Project Tomahawk, post launch assessment. Creative Research nternational. January 1997. Trial Exhibit D-237d: Bates pages 99001023-1063.

29 Tomahawk Communication Plan. March 1997, 15 pages. Tria Exhibit D-237e: no Bates pages.

30 Smoke Constituent Reporting Form. Player's Light King Size. March 2000. Trial Exhibit D-82. Smoke Constituent Reporting Form. Player's Premiere King Size. March 2000. Trial Exhibit D-83.

31 Rapport d'expertise d'André Castonguay. 17 March 2002, p 4. Tria Exhibit D-241

32 Bradley SD, Meeds R. Learning from advertisements: a comparison of prior word knowledge and explanatory context on meaning acquisition for technical terms. In: Abernethy AM, ed. Proceedings of the 2002 Conference of the American Academy of Advertising. Auburn, Alabama: Auburn University, 2002:32.

33 Ferris WG, Connolly GN. How cigarette design can affect youth initiation into smoking: Camel cigarettes 1983-93. Tobacco Control 2002;11 (suppl I):i32-9.

34 RBH-003587, 1994, p.8, as cited in Pollay RW. Trial Exhibit D-57. Op cit. 